\title{
PREPARASI DAN KARAKTERISASI NANOSILIKA DARI JERAMI PADI
}

\author{
Emas Agus Prastyo Wibowo ${ }^{\left.{ }^{*}\right)}$, Adi Wahyu Arzanto ${ }^{1)}$, Khoironni Devi Maulana ${ }^{\text {() }}$ \\ Aden Dhana Rizkita ${ }^{1)}$
1) Jurusan Kimia Universitas Negeri Semarang, Semarang, 50229, Indonesia
*) Coresponding author: emasagus@ymail.com
e-mail:adiwahyuarzanto@gmail.com;
dm.khoironni@students.unnes.ac.id,dm.khoironni@students.unnes.ac.id

\begin{abstract}
ABSTRAK
Penelitian ini dilakukan untuk mengetahui karakteristik silika yang diekstraksi dari jerami padi yang diperoleh dari wilayah usaha tani padi Pekalongan. Silika diperoleh dengan metode sol-gel, yang melibatkan ekstraksi silika dengan larutan alkali dan gelasi silika menggunakan larutan asam. Ditemukan bahwa hasil tertinggi diperoleh dari ekstraksi menggunakan larutan $\mathrm{KOH} 5 \%$ dengan waktu ekstraksi 60 menit, dan $\mathrm{pH}$ gelasi 7.0. Persiapan berhasil diproduksi dengan memanaskan jerami padi pada suhu $10{ }^{\circ} \mathrm{C} /$ menit dan menahannya pada suhu $500^{\circ} \mathrm{C}$ untuk memudahkan penguraian dan pengadopsian bahan organik sambil menghindari pengapian otomatis. Komposisi kimia $\mathrm{SiO}_{2}$ diperkuat oleh EDS dan FTIR dan sifat amorf oleh XRD.Serbuk nanosilika dengan ukuran pori rata - rata 45,3869 nm dan memiliki permukaan spesifik $(94,761$ $\left.\mathrm{m}^{2} / \mathrm{g}\right)$.
\end{abstract}

Kata kunci: Jerami padi; Nanopartikel silika, Sol gel

\section{PREPAPARATION AND CHARACTERIZATION NANOSILICA FROM RICE STAW}

\begin{abstract}
This study was carried out to investigate the characteristics of silica extracted from rice straw obtained from rice farming region of Pekalongan. The silica was obtained using sol-gel method, which involves extraction of silica using alkalis solution and gelation of the silica using acid solution. It was found that the highest yield was obtained from the extraction using $5 \% \mathrm{KOH}$ solution with the extraction time of 60 minutes, and gelation $\mathrm{pH}$ of 7.0. Preparation was successfully produced by heating rice straw at $10{ }^{\circ} \mathrm{C} / \mathrm{min}$ and holding at $500^{\circ} \mathrm{C}$ to facilitate decomposition and gasification of the organics while avoiding auto-ignition. $\mathrm{The}^{\mathrm{SiO}} \mathrm{S}_{2}$ chemical composition was confirmed by EDS and FTIR and the amorphous nature by XRD. Nanosilica powders with a 45,3869 $\mathrm{nm}$ average pore size and have specific surface $\left(94,761 \mathrm{~m}^{2} / \mathrm{g}\right)$.
\end{abstract}

Keywords: Rice straw; Silica nanoparticles, Sol gel

\section{PENDAHULUAN}

Nanoteknologi telah menarik banyak ilmuwan karena potensi penggunaan partikel dalam skala 1-100 nanometer (Stone et al. 2010). Dalam skala nano, sifat fisik, kimia, dan biologis berbeda dari sifat atom individu dan molekul materi massal. Oleh karena itu, hal ini memberikkan peluang untuk pengembangan penelitian baru terkait material maju yang memenuhi permintaan dari aplikasi berteknologi tinggi (Kharisov et al. 2010). Dengan cepat berkembangnya berbagai aplikasi nanomaterial di beberapa bidang telah diamati dalam beberapa tahun terakhir (Kharisov et al. 2010). Di antara beberapa aplikasi, nanosilika adalah nanomaterial yang banyak digunakan dengan aplikasi polimer perekat, untai serat optik, tinta, cat, pelapis, kosmetik, aditif makanan, dan bahan bangunan berbasis semen(Hessien et al., 2009). Nanosilika adalah salah satu nanofiler paling umum yang digunakan dalam pembuatan nanokomposit (Dorigato et al. 2012). Sumber silika dengan nilai silika rendah diubah menjadi jenis silika bernilai tambah dengan berbagai proses (Zaky et al. 2008). Produk silika yang 
dihasilkan, umumnya diklasifikasikan berdasarkan sifatnya termasuk nanosilika, silika berasap, silika yang diendapkan, silika koloid, dan silika gel (Jal et al. 2004). Aplikasi nanosilika pada akhirnya bergantung kepada kimia permukaan, struktur molekul, morfologi, dan porositas (Sun et al. 2004). Oleh karena itu, modifikasi nanopartikel silika untuk meningkatkan sifat kimia dan fisik permukaan adalah kunci keberhasilan aplikasi material (Guo et al. 2008).

Solusi terbaik yang dapat dilakukan untuk menghasilkan nanosilika adalah dengan memanfaatkan limbah pertanian yakni jerami padi. Jerami padi dibakar setelah produk padi dikumpulkan, yang disebabkan oleh adanya peningkatan elemen nutrisi tanah untuk pengembangan tahun berikutnya, serta menghilangkan kebutuhan akan penyimpanan jerami. Namun, di negara maju, konsep "bahan limbah" tidak lagi berlaku, karena semua bahan limbah dianggap sebagai sumber untuk menghasilkan produk baru dan meningkatkan nilai tambah. Studi ini telah membuktikan bahwa jerami padi, bahan limbah proses pertanian, mungkin merupakan kandidat potensial (Hessien et al., 2001). Namun, masalah utama adalah tumpukan abu jerami padi (RSA) yang akan silika (Hessien et al., 2009; Agbagla et al., 2001; Husnain, 2011). Kandungan silika yang dikumpulkan dengan jerami padi, jauh lebih besar daripada tanaman lainnya karena jerami padi mengandung bahan organik sebagai berikut: Selulosa : 32-47\%, Hemi selulosa: 19,27\%, Lignin: 5-24\%, Abu: 13-20 $\%$ (Zaky et al., 2008). Abu jerami padi memiliki 60\% silika (Santos et al., 2010) yang tentu saja, dilaporkan berbeda dalam kondisi iklim yang berbeda, tergantung pada jenis tanah, musim budidaya padi, kondisi cuaca dan geografi.

Keunggulan silika yang berbahan baku limbah pertanian padi dibandingkan silika yang diperoleh dari deposit batuan (kuarsa) adalah (1) silika dari sekam ataupun jerami padi memberi nilai tambah terhadap limbah pertanian, sedangkan silika dari batuan menyebabkan kerusakan lingkungan akibat deposit, (2) silika dari sekam atau jerami padi amorf dan reaktif serta tidak memerlukan banyak energi ketika ditransformasi ke struktur kritobalit, sehingga cocok untuk bahan awal dalam menghasilkan silika, dan (3) silika dari sekam atau jerami langsung dapat berupa bubuk dengan kemurnian tinggi serta memurnikannya mudah sedangkan untuk mendapatkan silika bubuk murni dari batuan kuarsa memerlukan banyak energi untuk penggilingan dan pemurnian. Selain silika amorf, jerami dan sekam padi juga dapat menghasilkan (1) karbon aktif yang memiliki luas permukaan spesifik $1517 \mathrm{~m}^{2} / \mathrm{g}$ dan mempunyai kemampuan absorbsi yang baik terhadap fenol, logam-logam berat dan ammonia-nitrogen (Kim and Choi, 1998, Karyasa, 2014). Penggunaan $\mathrm{Si}$ yang molekulnya berskala nanometer $\left(10^{-9} \mathrm{~m}\right)$ diharapkan akan memiliki keunggulan dibandingkan dengan penggunaan $\mathrm{Si}$ yang biasa. Penelitian ini diharapkan akan memberikan manfaat yang besar karena informasi mengenai penerapan nanoteknologi khususnya nanosilika pada bidang pertanian di Indonesia masih belum begitu banyak dilakukan terutama yang menggunakan jerami sebagai bahan bakunya. Tujuan penelian ini untuk mengetahui karakteristik nanosilika yang didapat dari bahan jerami padi.

\section{METODE PENELITIAN}

\section{Alat dan Bahan}

Bahan yang digunakan adalah jerami $\mathrm{KOH}, \mathrm{HCl}, \mathrm{H}_{2} \mathrm{SO}_{4}, \mathrm{NH}_{4} \mathrm{OH}$ dan aquades. Alat yang digunakan adalah hot plate, pengaduk, tungku pembakaran, gelas beker, erlenmeyer, oven, reflux, termometer, XRD, FTIR, dan SEM.

\section{Preparasi Abu Jerami Padi}

Jerami padi dibersihkan dari pengotornya dan dikeringkan dibawah terik matahari. Seteleh kering jerami di panaskan pada suhu $700 \quad{ }^{\circ} \mathrm{C} \quad$ selama 4 jam menggunakan furnace hingga terbentuk abu berwarna putih. Abu berwarna putih digerus dan diayak menggunkan ayakan 200 mesh (Agung et al., 2013).

\section{Ekstraksi Silika dari Abu Jerami Padi}

Sebanyak 20 gr abu jerami dilarutkan dalam $160 \mathrm{ml} \mathrm{KOH} 3 \mathrm{M}, 3,5 \mathrm{M}$ dan 4 M. Larutan ditutup kemudian dipanaskan dan diaduk menggunakan stirrer menggunakan hot plate pada suhu $85{ }^{\circ} \mathrm{C}$ 
selama 3 jam. Larutan disaring, residu dicuci menggunakan $40 \mathrm{ml}$ aquades. Larutan didinginkan pada suhu ruangan kemudian ditambahkan $\mathrm{HCl} 1 \mathrm{M}$ secara perlahan sambil diaduk sampai $\mathrm{pH}$ 7. Larutan dibiarkan pada suhu ruang selama 3,5 jam. Larutan disaring, endapan dikeringkan dalam oven (Kalapathy et al., 2000).

Silika murni direfluks menggunakan $\mathrm{HCl} 6 \mathrm{M}$ selama 4 jam kemudian dicuci menggunakan aquades hingga bebas asam. Larutan dilarutkan dalam $\mathrm{NaOH} 2,5 \mathrm{~N}$ dilanjutkan pengadukan menggunakan magnetic stirrer selama 6 jam. Ditambahkan $\mathrm{H}_{2} \mathrm{SO}_{4}$ pekat sampai $\mathrm{pH}$ 8. Endapan dicuci menggunakan aquades hangat hingga bebas basa kemudian dikeringkan dalam oven (Rafiee et al., 2012).

\section{Karakterisasi}

Untuk mengetahui struktur, difraksi sinar X (XRD) dilakukan menggunakan difraktometer Phillips PW1800. Phillips PW1480 juga digunakan untuk menentukan komposisi kimia RSA dan kemurnian silika yang dilakukan sintesis melalui spektroskopi dispersi energi sinar $\mathrm{X}$ (EDS). Untuk mempelajari morfologi silika dengan menggunakan Scanning Electron Microscopy (SEM). Untuk mempelajari stabilitas termal silika menggunakan analisis termogravimetri (TGA-50, Shimadzu, Japan). Sampel dipanaskan dalam suhu 10 ${ }^{\circ} \mathrm{C} /$ menit dari 30 to $600{ }^{\circ} \mathrm{C}$ dalam udara yang berpijar $30 \mathrm{~mL} /$ menit. Akhirnya, uji BET dilakukan untuk menentukan luas permukaan spesifik.

\section{HASIL DAN PEMBAHASAN}

\section{Karakterisasi dengan FTIR}

Silika yang diperoleh dari sekam padi dengan metode ekstraksi dianalisis dengan FTIR dan spektrumnya diperlihatkan pada Gambar 1. Puncak utama yang diyakini berkaitan dengan gugus fungsi pada silika adalah pada bilangan gelombang 3448,72 $\mathrm{cm}^{-1}$.Puncak ini merupakan puncak yang khas untuk vibrasi ulur gugus - $\mathrm{OH}$ (gugus hidroksil). Dengan demikian, dalam silika yang digunakan sebagai sampel diyakini terdapat gugus hidroksil, yang menunjukkan ikatan Si-OH atau silanol (Lin et al., 2001; Lai, 2013; Mourhly et al., 2015), meskipun sumbangan gugus hidroksil dari molekul air yang terhidrasi juga tidak dapat diabaikan (Daifullah et al., 2003). Puncak kedua yang diyakini menunjukkan gugus fungsi silika adalah puncak pada bilangan gelombang $1103,28 \mathrm{~cm}^{-1}$,yang menunjukkan adanya gugus fungsi siloksan Si-O-Si (Daifullah et al., 2003, Adam et al., 2006; Nandiyanto et al., 2016; Lu and Hsieh, 2012; Rafiee et al., 2012). Adanya gugus fungsi Si-O-Si diperkuat dengan adanya puncak pada bilangan gelombang 470,63 $\mathrm{cm}^{-1}$,yang menunjukkan ikatan Si-O (Linet al., 2001; $\mathrm{Lu}$ and Hsieh, 2012), puncak pada 802,39 $\mathrm{cm}^{-1}$, yang timbul akibat deformasi ikatan Si-O pada $\mathrm{SiO}_{4}$ (Liou, T.H, 2004; Liu et al., 2011; Rahman et al., 2009).

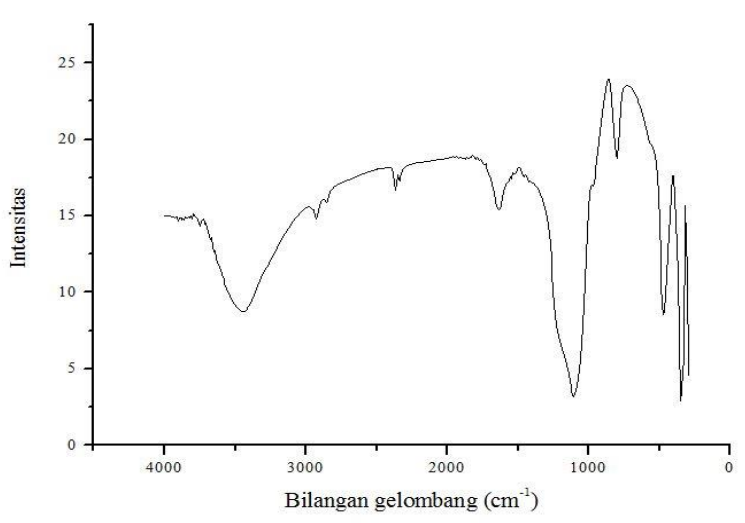

Gambar 1. Spektrum FTIR Silika yang Diperoleh dari Jerami Padi

Puncak lain dengan intensitas yang cukup signifikan terdapat pada daerah $1635,64 \mathrm{~cm}^{-1}$. Puncak ini menunjukkan vibrasi regang $\mathrm{C}=\mathrm{O}$ dari hemiselulosa, yang kemungkinan ikut terlarut pada saat ekstraksi dan teradsorbsi oleh silika serta ikatan H-O-H. Puncak lemah lainnya terdapat pada daerah $972,12 \mathrm{~cm}^{-1}$, yang menunjukkan adanya ikatan antara Si-O dengan logam. Interpretasi data IR ini bersesuaian dengan analisis fungsional yang dilakukan oleh Kamath dan Proctor (1998). Puncak muncul pada $3750 \mathrm{~cm}$ yang menunjukkan adanya ikatan hidrogen yang dihasilkan dari interaksi antara gugus silanol (Si-OH) yang terletak pada permukaan bahan nanosilika (Yang and Wang, 2006). 


\section{Karakterisasi dengan XRD (X-Ray Diffraction)}

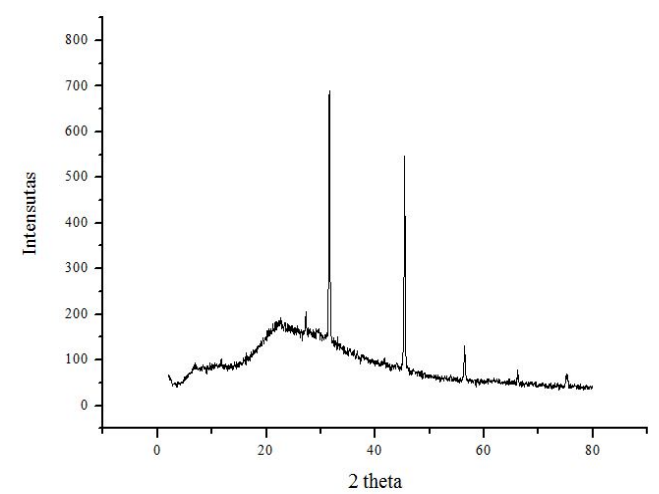

Gambar 2. Silica dari jerami padi

Analisis struktur kristal silika dilakukan dengan menggunakan difraksi metode sinar-X. Fase yang terdeteksi dalam kromatogram selanjutnya diidentifikasi dengan menggunakan metode pencocokan memanfaatkan perangkat lunak Origin. Spektrum yang diperoleh disajikan pada Gambar 4. Pola difraksi yang dihasilkan menunjukkan bahwa silika yang terbentuk adalah amorf, dengan tambahan fase yang memiliki puncak tertinggi pada $2 \theta=31,46$ dan 50,16 . Tidak ada fase yang muncul pada $(2 \theta)=22^{\circ}$. Berdasarkan tabel di atas, puncak primer utama dari difaktogram kristobalit dan polimorfi kuarsa muncul sebagai fase pendamping, dan polimorfi tridimit tidak muncul. Hal ini sesuai dengan penelitian dari Karyasa (2014). Nanosilika

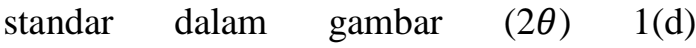
menunjukkan puncak yang kuat pada 22.14 yang merupakan karakteristik silika amorf (Singh et al. 2008), Kalapathy $d k k$. (2000). Ukuran kristal nanosilika berdasarkan persamaan adalah 45,3869 $\mathrm{nm}$.

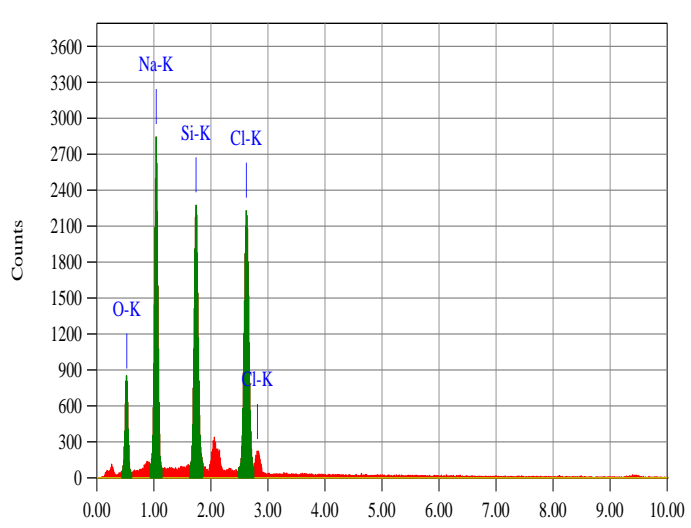

$\mathrm{keV}$

Gambar 3. Spektrum EDS dan Komposisi Sampel

Komposisi kimia silika diperkuat oleh EDS (Gambar. 3) yang menunjukkan $\mathrm{Si}$ dan $\mathrm{O}$ pada rasio atom 1:2 yang dihitung. Tidak adanya unsur lain, seperti $\mathrm{C}, \mathrm{K}, \mathrm{Na}$, $\mathrm{Cl}$, dilaporkan dalam jerami padi (Wu et al., 2009), juga memastikan bahwa pencucian bubuk jerami padi dengan air sebelum pemanasan efektif dalam menghilangkan logam tersebut. Pengotor logam juga dilaporkan terbawa dengan volatil selama dekomposisi panas jerami padi (Liou, 2004). Perpisahan strategis pada suhu kritis ini dan memperpanjang proses pemanasan mungkin telah meningkatkan efisiensi ini.

\section{Luas Permukaan dan Porositas}

Luas permukaan dari bubuk silika dari analisis Brunauer-Emmett-Teller (BET) adalah $509.5 \mathrm{~m}^{2} / \mathrm{g}$ (Tabel 1). Permukaan spesifik ini jauh lebih rendah dari $326,9 \mathrm{~m}^{2} /$ gram untuk silika komersial.

Tabel 1. Karakteristik permukaan dan karakteristik pori serbuk silika yang disiapkan oleh BET dari isoterm adsorpsi nitrogen, data silika komersial juga disediakan untuk perbandingan

\begin{tabular}{ll}
\hline Sampel & $\begin{array}{l}\text { Luas Permukaan } \\
\text { BET }\left(\mathrm{m}^{2} / \mathrm{g}\right)\end{array}$ \\
\hline $\begin{array}{l}\text { Silika dari Jerami } \\
\text { Padi }\end{array}$ & 94,761 \\
\hline Silika Komersial & 326,9 \\
\hline
\end{tabular}




\section{KESIMPULAN}

Nanosilika berhasil diekstraksi melalui pelepasan asam - asam endapan abu jerami padi, analisis EDS menegaskan bahwa produk turunannya mengandung $\mathrm{Si}$ dan O. Silika dalam analisis FTIR yang diperoleh sesuai dengan silika murni yang tersedia secara komersiall. Selanjutnya, sifat amorf silika diperkuat oleh XRD. Serbuk silika amorf kering-beku ini dengan ukuran pori rata - rata sebesar $45,3869 \mathrm{~nm}$.

\section{DAFTAR PUSTAKA}

Agbagla-Dohnani A, P.Nozière, G. Clément, M. Doreau. 2001. Chemical and morphological composition of 15 varieties of european rice straw. Anim Feed Sci Technol 94: 15-27.

Arryanto, Y.S.A., M.F. Rosyid, A. Rhaman, P. Artsanti. 2007. Iptek Nano di Indonesia. Deputi Bidang Perkembangan Riptek Kementerian Negara Ristek dan Teknologi. 206 Hal. ISBN 979-24-0571-2.

Daifullah, A.A.M., B.S. Girgis, and H.M.H Gad. 2003. Utilization of AgroResidues (Rice Husk) in Small Waste Water Treatment Plans. Material Letters 57:1723-1731.

Dorigato A., M. Sebastiani and A. Pegoretti. 2012. Effect of silica nanoparticle on the mechanical performances of poly (lactic acid). Journal of Polymers and Environment 20: 713-725.

Guo Y., M. Wang, H. Zhang, G. Liu, L. Zhang and X. Qu. 2008. The surface modification of nanosilica, preparation of nanosilica/acrylic coreshell latex, and is application in toughening PVC matrix. Journal of Applied Polymer Science 107: 26712680.

Hessien M. M., M.M. Rashad, R.R. Zaky, . E.A. Abdel-Aal and K.A. El-Barawy. 2009. Controlling the synthesis conditions for silica nanosphere from semiburned Rice straw. Materials Science and Engineering B, 162: 1421.
Jal P.K., M. Sudarshan, A. Saha, S. Patel and B.K. Mishra. 2004. Synthesis and characterization of nanosilica prepared by precipitation method. Colloids and Surfaces A: Physicochemical and Engineering Aspects 240: 173-178.

Kalapathy U., A. Proctor and J. Shultz. 2000. A simple method for production of puresilica from rice hull ash. Bioresource Technology 73: 257-262.

Kamath,S.R and A. Proctor. 1998. Silica gel from rice hull ash: preparation and characterization. Cereal Chemistry 75, 484-487.

Kharisov B.I., O.V. Kharissova and M. JoseYacaman. 2010. Nanostructures with animal like shapes. Industrial and Engineering Chemistry Research 49: 8289-8309.

Lai C Y. 2013. Mesoporous nanomaterials applications in catalysis. Journal of Thermodynamics \& Catalysis 5:1-3. DOI: 10.4172/2157-7544.1000e124.

Lin, J., J.A. Siddiqui and M. Ottenbrite. 2001. Surface Modification of Inorganic Oxide Particles with Silane Coupling Agent and Organic Dyes. Polymer Advance Technology, 12:285-292.

Liou,T.H. 2004. Preparation and characterization of nano-structured silica from rice husk, Materials Science and Engineering a-Structural Materials Properties Microstructure and Processing 364, 313-323.

Liu, Y., Y. Guo, D. Zhu, W. Gao, Z. Wang. 2011. A sustainable route for the preparation of activated carbon and sil ca from rice husk ash. Journal of Hazardous Materials 186, 13141319.

Lu, P., Y.L. Hsieh. 2012. Highly pure amorphous silica nano-disks from rice straw. Powder Technology. 225 149155. 
Mourhly, A., M. Khachani, A.E. Hamidi, M. Kacimi, M. Halim and S. Arsalane. 2015. The Synthesis and Characterization of Low-Cost Mesoporous Silica $\mathrm{SiO}_{2}$ from local Pumice Rock. Nanomaterials and Nanotechnology (DOI: 10.5772/ 62033).

Rafiee, E., S. Shahebrahimi, M. Feyzi, M. Shaterzadeh. 2012. Int. Nano Letters 21.

Ranjbar, M and G.A. Shams. 2009. Using of Nanotechnology. Journal of Environment Green, 3: 29-34.

Santos, M.B., G.A. Nader, P.H. Robinson, D. Kiran, U. Krishnamoorthy and M.J. Gomes. 2010. Impact of simulated field drying on in vitro gas production and voluntary dry matter intake of rice straw. Anim Feed Sci Technol 159: 96-104.

Silva, J.A. 1981. Possible mechanism for crop response to silicate application. Proc.nt.Sym.Soi; Fertilities Evaluation, New Delhi, 1:805:814.

Singh D., R. Kumar, A. Kumar and K.N. Rai. 2008. Synthesis and characterization of rice husk silica, silica-carbon composite and $\mathrm{H}_{3} \mathrm{PO}_{4}$ activated silica. Ceramica 54: 203-212.

Sitorus. 2004. Pengujian Pupuk Phonska Pada Tanaman Jagung Hibrida Varietas Pioner Pada Inteceptisol Dari Cibugel, Sumedang. Skripsi. Dipublikasikan. Program Studi Ilmu Tanah (S1). Departemen Tanah. Fakultas Pertanian. Institut Pertanian Bogor.

Stone V., B. Nowack, A. Baun, N.V.D. Brink, F.V.D. Kammer, M. Dusinska, R. Handy, S. Hankin, M. Hassellov, E. Joner and T.F. Fernandes. 2010. Nanomaterials for environmental studies: Classification, reference material issues, and strategies for physico-chemical characterization. Science of the Total Environment 408: 1745-1754.
Sudibyo, B.S. 2008. Pengaruh Pemberian $\mathrm{Si}$ terhadap Serapan $\mathrm{Si}$ dan hasil Jagung (Zea mays., L) pada Andisol. Skripsi. Srjana S1 Fakultas Pertanian UGM Yogyakarta.

Sun Q., E.G. Vrieling, R.A. Van-Santen and N.A.J.M Sommerdijk. 2004. Current Opinion in Solid State and Material Science 8: 111-120.

Suwardjono. 2001. Pengaruh Beberapa Jenis Pupuk Kandang terhadap Pertumbuhan dan Produksi Kacang Tanah. Jurnal Matematika, Sain dan Teknologi. 2 (2): 11-18.

Wu,Y.Q., S.Y. Wu, Y. Li and j.s. Gao. $2009 . \quad$ Physico-chemical characteristics and mineraltransformation behavior of ashes from crop straw. Energy \& Fuels 23 51445150 .

Yang J, E. Wang. 2006. Reaction of water on silica surfaces. Current Opinion in Solid State and Materials Science 10:33-39. DOI: $10.1016 /$ j.cossms. 2006.02.001.

Zaky R. R., M.M. Hessien, A.A. El-Midany, M.H. Khedr, E.A. Abdel-Aal and K.A ElBarawy. 2008. Preparation of silica nanoparticles from semi-burned rice straw ash. Powder Technology 185: 31-35. 